\title{
CORONARY THROMBOSIS: COAGULATION STUDIES RELATED TO THE LOCAL EVENTS
}

\author{
J. R. O'BRIEN, M.A., D.M., M.R.C.S., M.R.C.P. \\ Consultant Haematologist to the Portsmouth and I.O.W. Area Pathological Service, Portsmouth, Hants.
}

Most coagulation research has been concerned with unravelling the chain of events leading to fibrin formation when a small sample of stationary blood is exposed to glass. Such studies must bear an important relation to events in vivo, since, for example, haemophilic blood is abnormal when examined in a glass tube and haemophiliacs bleed. The application of coagulation methods in patients with coronary thrombosis assumes implicitly that thrombus formation is dependent on an over-active clotting mechanism. That this assumption may not be justified is suggested by the clinical observation that haemophiliacs and patients being treated with anticoagulants, who certainly have coagulation defects, may suffer from coronary thrombosis. A short survey of some coagulation studies in coronary disease will, therefore, be preceded by a detailed consideration of some local events preceding the formation of a thrombus and the relevance of the coagulation mechanism to these events.

\section{Local Events During Thrombus Formation}

A thrombus occurs at a particular site and the whole blood stream never clots solid, so it can be deduced that there must be some local change which determines the site of thrombosis. This change must be either a unique change in the vessel wall, or a unique hydrodynamic situation, or possibly a change in the state of all the circulating blood so that it is hyper-reactive to the two local alterations, either or both of which might occur frequentiy.

Little is known about hydrodynamic changes that might precipitate thrombus formation. In veins, which will not be discussed here, stasis clearly predisposes to thrombus formation (or is it clotting?). It seems possible that back eddies in the stream of coronary blood may facilitate thrombus formation, but it is doubtful if they are ever the initial event, and thus they will not be further considered.

What, then, is the nature of the unique local change in the surface of the vessel wall, aided perhaps by back eddies, perhaps by hyper-reactive blood, which determines the formation of a throm? bus at one particular site in the coronary vessel g్ The precise answers are unknown, but we cans consider the kind of change that would be neces $\overrightarrow{0}$ sary to initiate the events leading to thrombus formation. A thrombus may be composed mainlyo of fibrin (and this may be of determinative clinicaB importance) or, more likely, it may be composedprimarily of platelets that have undergone viscousd metamorphosis ; it is, however, safe to assume tha the adhesion of at least a few platelets is the first essential step, whether the main thrombus mass consists of further platelets or of fibrin. Tofe question asked above can now be paraphrase what local change in the endothelium leads $\bar{q}_{0} \circ$ adhesion of platelets and how do the plateletso stick? It is probably agreed that normal platelets in the blood stream sweeping past normab endothelium do not stick, at least not in sufficiento numbers to produce a thrombus. If the vesse $\mathbb{B}$ wall is damaged, platelets stick to the damaged area very rapidly. Hughes ${ }^{13}$ has photographs and 3 cinematograph films showing platelets adhering to a severed venule in two seconds. Platelets in whole native un-anticoagulated blood can also stick to glass in two seconds. In this short space of time a message must pass through the plasma to the platelet, which is then almost certainly attracted. and becomes 'sticky'. The damaged endothelium? changed plasma and sticky platelets are indicated in Fig. I. It is hard for a coagulationist to accept that the activation of the known coagulation factors $\triangle$ could be fast enough to allow them to be con-․ㅡ. cerned in this very rapid adhesion: it should, however, be appreciated that there is virtually no information about the speed of the coagulation 0 processes at or near a surface: it may be in comparably faster than in the bulk of the clotting blood.

It has recently been shown. ${ }^{23}$ that 'damaged $\stackrel{0}{\bar{D}}$ endothelial cells, as opposed to intact cells, have $a^{\text {p }}$ weak 'brain-like' action on clotting, as well as ' available' cephalin* sites, and they also have the 


\section{Diagrammatic representation of possible}

events leading to thrombus formation.
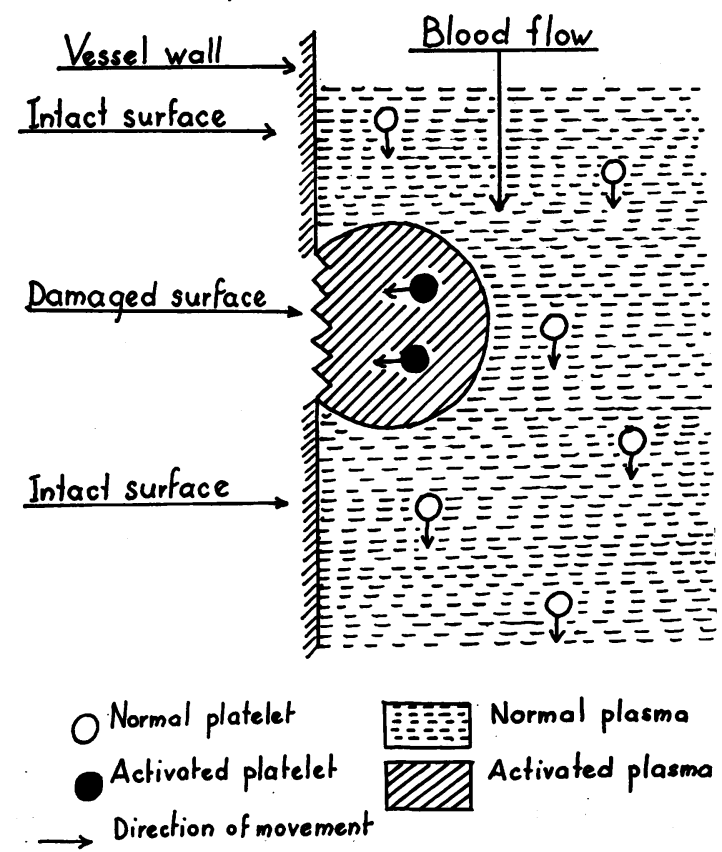

FIG. I.

ability to combine with and inactivate heparin. It is, however, not known if any of these properties are relevant to the initiation of platelet adhesion.

Intact endothelium (water wettable) and siliconed surfaces (non-wettable) do not initiate clotting or induce platelets to stick, while damaged cells or a glass surface trigger off both processes. It has thus been frequently assumed that the kind of trigger mechanism that initiates clotting is the same as that causing platelet adhesion. This, however, may not be justified. The earliest known event in the chain of reactions leading to clotting in glass is the activation of Hageman factor, and the blood of patients with Hageman trait clots abnormally in glass, yet it has recently been shown that their platelets in native blood or plasma stick normally to glass and to each other. ${ }^{24}$ It may be concluded that at least in glass tubes the trigger mechanism initiating clotting is not identical with that initiating the platelet adhesion.

\footnotetext{
* 'Available' cephalin sites are assumed to be present if a cell surface which contains cephalin has clotting activity similar to that of platelets or isolated cephalins. The molecules in the cell surface may be so arranged that the cephalin molecules are ' unavailable' and inactive in clotting tests, as, for example, in an intact red cell.
}

Changes in the plasma necessary to induce the platelet to stick are hard to separate from changes in the platelet, since platelets, at any rate by the time they are studied in the laboratory, are surrounded by an absorbed layer of plasmal'atmosphère periplaquetaire of Roskam. It is known that calcium ions are essential for sticking, since cecalcification prevents adhesion and it is very probable that Hageman factor, anti-haemophilic factor, Christmas factor, factor VII, etc., and fibrinogen and heparin in moderate doses, play no part in platelet adhesion, since platelets in these abnormal plasmas stick normally to glass ${ }^{24}$ and probably to endothelial cells, since the bleeding time is essentially normal in these conditions.

The formation of a clou hemostatique-the occlusive plug of platelets in a damaged vesseland the normal short bleeding time are dependent on the adhesion of platelets to a severed vessel. Diseases with a long bleeding time may have abnormal vessels (cut telangiectases bleed excessively) or abnormal plasma or platelets. Patients with von Willebrand's disease have a long bleeding time and they also may have a moderately decreased plasma A.H.G. level and may have abnormal capillaries. Recently, however, Nilsson, Blomback and Blomback ${ }^{20}$ have shown that these patients lack a factor present in normal plasma, which is not anti-haemophilic globulin, that restores the bleeding time to normal. This suggests that capillary bleeding and presumably platelet adhesion is related to this plasma factor. Yet in a small study of blood from these patients the adhesion of platelets to glass and to each other was normal. ${ }^{24}$ This disease merits further investigation.

What changes in the platelets are necessary to induce their adhesion are again unknown and are particularly difficult to study, since any manipulations during the investigation of their surface properties are likely to alter that surface. 'Intact' ' uncontacted' platelets in native blood do not adhere to each other. Exposure of the blood or plasma to a foreign surface induces adhesiveness of platelets to each other or to the foreign surface, and both these kinds of adhesiveness are inhibited by removing calcium ions or by some drugs such as Benadryl and cocaine. But it is not clear if these drugs are acting on the plasma or on the platelet surface. It has been shown in this laboratory that if native whole blood is made to flow for to seconds over intact live amnion cells growing in a confluent sheet on glass no platelets stick. If the sheet of amnion cells is first heated to $56^{\circ} \mathrm{C}$. (a model of damaged endothelium), then platelets stick (Fig. 2a). This phenomenon is also inhibited by Benadryl and cocaine (Fig. 2b). These damaged cells, in contrast to the intact cells, 


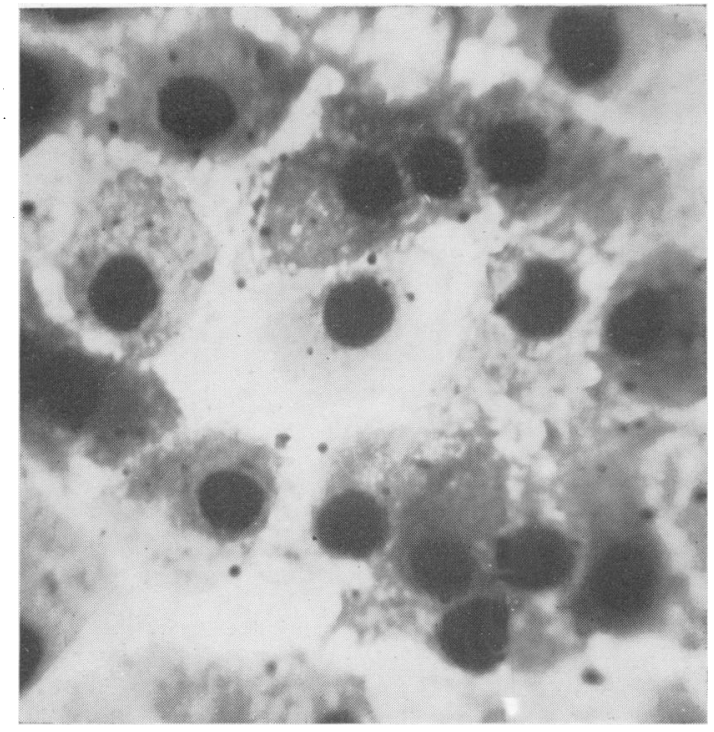

Fig. 2a.-Native blood dribbled for io seconds over amnion cells previously heated to $56^{\circ} \mathrm{C}$. for 30 minutes. Cells washed in formol saline, stained with aqueous cresyl blue. Many platelets are seen adhering to the 'damaged' cell surface. $\left(x_{1}, \infty 00\right)$

have cephalin sites exposed at their surface, since the damaged cells accelerate appropriate clotting tests. On the other hand, platelet fragments in native plasma do not stick and these are an excellent source of cephalin for clotting tests. ${ }^{24}$ There is thus no complete parallelism between ' available ' cephalin sites and adhesiveness. One possible explanation of the change in the platelet necessary to make it 'sticky' is the exposure of available cephalin sites. This conclusion is, however, tentative and it is realized that other explanations could fit the facts.

To summarize the process of platelet adhesion to a vessel wall, it seems likely that the initial stimulus comes from an alteration in the surface properties of the endothelium. The nature of this alteration is unknown, but similar changes occur in other ' damaged ' cells. Such damaged endothelial and other cells are also clot promoting, at least in the sense that cephalin sites become 'available' to take part in clotting processes. Normal plasma and calcium are essential to transmit the signal to the platelet. The factor missing in von Willebrand's disease may play a part, and there have been claims that Plasma Thromboplastin Antecedent ${ }^{28}$ may also or alternatively be involved. The nature of the change in the platelet necessary before it can stick is ill understood, but it may possibly be related to the exposure of cephalin sites. The final adhesion may be envisaged

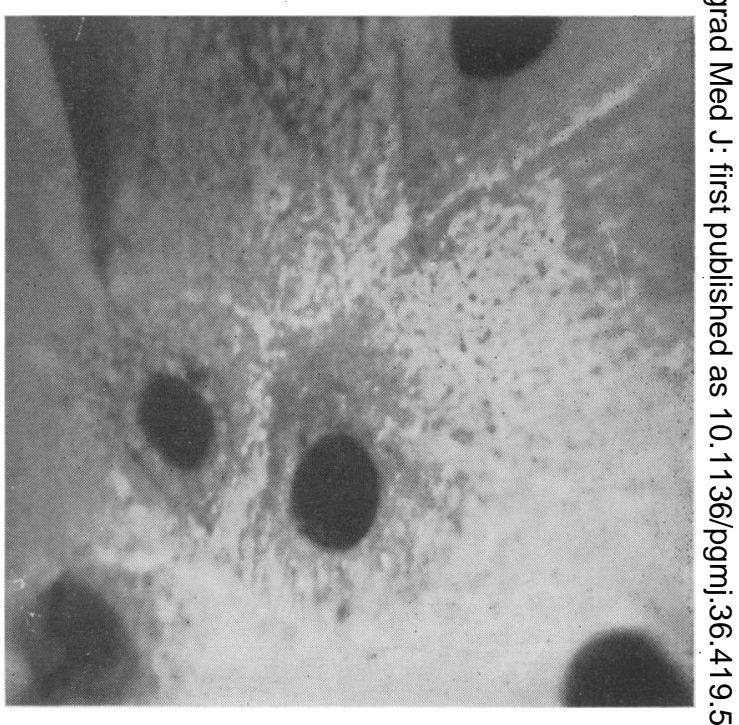

FIG. 2b.-Native blood mixed with one-tenth volume of $\infty$ benadryl, 10 mg. $/ \mathrm{ml}$. Other procedures as in Fig. 음 2a. No platelets adhere. $\left(x_{1}, 000\right)$

as two altered surfaces cemented together with an $\frac{}{\mathbb{D}}$ altered protein acting as cement.

It is possible that changes in the plasma cam $\mathbb{Q}$ increase or decrease the likelihood of plateled $\overrightarrow{0}$ adhering to the vessel, and certainly the processefs considered above are closely connected with ce agulation, i.e. fibrin formation, but it does not follow that the coagulation factors essential for fibrin formation are necessary for platelet adhesion. Indeed, platelets in aged blood and in Benadryl- $\frac{\square}{\triangle}$ treated blood do not stick and in both these $\varrho$ situations clotting is little affected (not at all with $\overrightarrow{\overrightarrow{0}}$ Benadryl). Here clotting proceeds in the absence of platelet adhesion: in Hageman's disease, haemophilia and other diseases in which clotting is defective, platelet adhesion appears to be normal 윽 in blood exposed to glass, but coagulation is abnormal. Thus it is possible that platelet 3 adhesion and fibrin formation are independent phenomena. The relative importance of a platelet $\frac{3}{3}$ mass (involving adhesion, viscous metamorphosis 0 and the adhesion of further platelets) and fibrin mass (coagulation) in the clinical condition of $\frac{D}{O}$ coronary thrombosis is not known with certainty, but the adhesion of some platelets must precede of local fibrin formation, since platelets play an N essential part in normal coagulation. The clotting స్ట of blood in the presence of a brain extract is, however, independent of platelets. Thus, the brainlike activity of damaged cells ${ }^{23}$ may be relevant to $\frac{0}{\stackrel{D}{D}}$ some in vivo situations.

In the argument above, reference has often been made to selected relevant work and to unconfirmed 
work in this laboratory, and in no way is this a review of the literature on the adhesiveness of platelets. Some other important work will now be mentioned. Of the few quantitative methods of measuring platelet adhesiveness, two ${ }^{18,30} \mathrm{em}$ ploy blood stabilized by heparinization or decalcification. A new method developed in this laboratory, in which native whole blood is passed rapidly over a large glass surface, seems more physiological and is proving useful. Dr. Hellem,* of Oslo, also is using a somewhat similar method. Other lines of approach must be mentioned, such as the adhesion of platelets to a variety of cells and special surfaces. ${ }^{8}$ Poole, ${ }^{25}$ using a modification of Chandler's method, ${ }^{9}$ produced clumps of platelets-' artificial thrombi '-in moving blood exposed to air in a rotating ring of plastic tubing half filled with blood. $\mathrm{He}$ emphasized that platelet aggregation can be independent of clotting.

Viscous metamorphosis, the change that is almost certainly essential before a firm platelet plug can be formed, has been studied, among others, by Sharp ${ }^{28}$ and Biggs et al.$^{6}$ and Zucker and Borrelli. ${ }^{31,32}$ The effect of antihistamines on platelet adhesiveness has been reported by Hughes. ${ }^{13}$ The importance of glycolysis to the contractile actomysin-like protein in platelets, studied by Luscher, ${ }^{14}$ is another fascinating aspect of the problem. Adhesion can be considered physio-chemically as the interaction of charged groups at the interface of the cells, ${ }^{2}$ and this concept may bear some relation to the flocculation of phospholipid micelles then attacked by a phospholipase. ${ }^{1,10}$ There is evidence of a plasma phospholipase activity during clotting. ${ }^{\text {? }}$

A more physiological approach has been used by the Liege School and by Fulton and others (e.g. Berman, Fulton, Lutz and Pierce ${ }^{5}$ ), who study the formation of thrombi in more or less intact animals by capillary microscopy. It has been claimed $^{26,27}$ that the normal intima carries a negative charge relative to the adventitia. Injury produces a reversal of this charge and thrombi occur, which are prevented by artificially maintaining the negative charge. Furthermore, in intact vessels an induced positive charge produces thrombi. The problems of thrombolysis and fibrinolysis will not be discussed.

\section{Coagulation Studies in Coronary Disease}

There have been many attempts to find some difference in the coagulation process of patients with coronary disease and that of normal controls. These efforts are presumably based on the supposition that if a difference exists it may be

*See addendum. related causally to the processes involved in either atheroma or thrombus formation. Further, it might be supposed that if this abnormality could be corrccted, atheroma or thrombus formation would cease. Clearly, both these suppositions may be false, but the gravity and complexity of coronary disease justifies almost any line of attack.

It is generally accepted that hyperlipaemia and hypercholesterolaemia predispose to or are associated with coronary artery disease. Barritt ${ }^{3}$ in England and Waldon, Chapman and Evans ${ }^{29}$ and others in the U.S.A. claim that on average postalimentary lipaemia is cleared more slowly in patients with coronary disease. Thus it is possible that fat transport and/or metabolism in these people differs from normal; this might be rclated to a difference in the heparin clearing system. It therefore becomes extremely important to know what coagulation tests are altered by hyperlipaemia, since clearly such changes might be causally related to the aetiology of coronary disease or they might simply be a coincidental result of the lipaemia.

Nitzberg, Peyman, Goldstein and Proger ${ }^{21}$ used many tests in a comparison of a small group of normal males with a group of hyperlipaemics and a group of hypercholesterolaemics. Some patients in the latter two groups had already had a coronary thrombosis. The stypven time was significantly shorter in the two groups with high blood fats than in the normal controls. They also found some evidence that on average more thromboplastin was produced by the groups with high blood fats. There are a number of claims ${ }^{15}, 22$ that the stypven time of platelet-poor plasma might be shorter in post-coronary patients, although Mersky, Gordon and Lackner ${ }^{16}$ found no difference; and there are many reports agreeing that the stypven time is shorter during postalimentary lipaemia.

It is very probable that the stypven time of platelet-poor plasma is dependent, among other things, on cephalin groups present either on platelet fragments, on chylomicrons or on some unspecified plasma lipid component in the plasma, other than the $\beta$ lipoproteins which are inactive. The. stypven time may, therefore, be regarded under these conditions as a biological estimation of ' available' cephalin groups. The relevance of these findings - at least to acute coronary thrombosis-may be doubted, since it is known that relatively vast amounts of cephalin-containing lipids have been given intravenously for nutritional purposes, but no thrombosis occurred; and there is no evidence ${ }^{17}$ that death from acute coronary thrombosis is more frequent following a large fatty meal.

In I960 Mersky and others ${ }^{16}$ published an ex- 
tensive and thorough investigation using many tests in a comparison of white controls, white patients with coronary disease and Bantus. They found that slightly more thromboplastin was generated in the patients than in the white controls. The Bantus-who have much less coronary disease than the whites-had in some tests apparently greater clotting activity, while in others they had less activity than the whites.

McDonald and Edgill ${ }^{15}$ compared patients with angina pectoris and patients with acute cardiac episodes with normals. They report a higher serum fibrinogen level and better thromboplastin generation in the patients. They also make the interesting claim that the stickiness of platelcts measured in the $\mathrm{Wright}^{\mathbf{3 0}}$ rotator is increased in. the patients.

Beaumont, Chevalier and Lenègrc ${ }^{4}$ and Gorm$\operatorname{sen}^{11}$ have reported that after a coronary thrombosis there is a shortening of the clotting time of blood or plasma in the presence of heparin-the heparin tolerance test-and there is some evidence that this test may be abnormal before the onset of the attack.

From a study of these and many other papers (e.g. Mustard ${ }^{19}$ and $\mathrm{O}^{\prime} \mathrm{Brien}^{22}$ ), in which various changes are reported by some workers but not confirmed by others, the accumulated evidence suggests that there probably is some difference in the coagulability of the blood during the acute phase. This, however, is not unexpected, since these patients have tissue damage and are ill with fever, a raised sedimentation rate, etc. The plasma of patients examined some time after the thrombosis may have slightly shorter stypven time, and more thromboplastin may be generated; the reastion to heparin may be abnormal and there is the exciting claim (as yet unconfirmed by others) that these patients' platelets are more adhesive to glass. Apart from platelet adhesiveness, the other tests may be related to the abnormal plasma lipid composition. The abnormal heparin tolerance test might be related to some possible abnormality of the heparin clearing system mentioned earlier. In general, however, it becomes apparent that the evidence in favour of the existence of any real change in these patients' blood is little stronger than that suggesting that there is no change.

During the formation of a coronary thrombus the situation in the patient's coronary artery must be completely different from that in the normal control subject. It is not known if this difference is local or general-a difference in all the circulating blood; and even if the blood is different, this difference may be episodic. We have so little idea of precisely what is the trigger mechanism that initiates thrombus formation that we do not know what kind of hyper-reactive state to look for. If some coagulation test is shorter (is this a hypercoagulable state?), this might well be the result of the thrombosis, or a coincidental ${ }_{\llcorner}$ finding related, for example, to the abnormal fat metabolism. Certainly a test that shows such as? small difference that it becomes significant onlyo on statistical analysis of large numbers of cases is $\underline{\bar{E}}$ likely to be far removed from the proximate cause $\frac{\overline{\bar{p}}}{\bar{D}}$ of the thrombus.

In conclusion, it would seem that the very considerable labour and ingenuity that has been ${ }_{\vec{c}}$ devoted to comparative coagulation studies has.yielded meagre results. This might be expected if $\vec{\omega}$ the coagulation mechanism as studied in glass tubes $\sigma$ bore little relation to the phenomena involved in thrombus formation. It would, therefore, seem 3 . more appropriate to devote more energy to studying $\omega_{\sigma}$ the mechanism of thrombus formation. Clues $A$ derived from such studies might then suggest tests, $\overrightarrow{0}$ which may not be ' coagulation tests', that could $G$ be applied to post-coronary patients or coronary- $\infty$ prone groups.

\section{Addendum}

Since the preparation of this paper Hellem has $\frac{\mathbb{D}}{\mathbb{O}}$ published (Suppl. Scand. F. Clin. and Lab. Invest, З 12, 1960) a full and up-to-date review of work onष the adhesiveness of platelets, to which the igterested reader is referred. $\mathrm{He}$ also reports $\mathrm{is}$. own extensive studies on the adhesiveness $\mathrm{gf}^{\circ}$ platelets in citrated blood and plasma, while the present writer has used primarily native blood. ${ }^{24}$ However, our findings agree on many points. Heō reports that when using citrated plasma, plateletső stick poorly to glass, while in citrated blood theyo stick in far greater numbers (and this phenomenon $\vec{\circ}$ also occurs in native blood ${ }^{24}$ ). He concludes that 3 a factor $R$ is released from red cells on contact? with a foreign surface which then causes the platelets to stick.

\section{Acknowledgments}

The unpublished work was carried out while $\mathrm{H}_{\mathrm{B}}^{3}$. was in receipt of a research grant from the Wessex Regional Hospital Board, which is gratefully acknowledged. It is also a pleasure to thank Mrs. 음 S. B. Duke for her technical assistance.

\section{REFERENCES}

I. BANGHAM, A. D., and DAWSON, R. M. C. (1959), Biochem. ज F., 72, 486.

2. BANGHAM, A. D., PETHICA, B. A., and SCAMEN, G. V. F. (1958), Ibid., 69, I 2.

3. BARRITT, D. W. (1956), Brit. med. F., ii, 640.

4. BEAUMONT, J., CHEVALIER, $H$., and LENEGRE, J: (1953), Amer. Heart F., 45, 756.

5. BERMAN, H. F., FULTON, J. P., LUTZ, B. R., and PIERCE, D. L. (I955), Blood, ro, 83 I.

6. BIGGS, R., SHARP, A. A., MARGOLIS, J., HARDISTY, R. M., STEWART, J., and DAVIDSON,'W. H. (1958), Brit. Э. Haemat., 4, i77.

Continued on page 569. 
coagulation and thrombosis. This has been based on dietetic surveys, sociological, clinical and laboratory studies. The effects of fats have been studied on clotting in vitro and the effects of fatty meals in the human subject by numerous authors. The association between abnormal lipoproteins and a predisposition to thrombosis has been studied.6,10 From the vast amount of evidence accumulated it appears that fat and particularly animal fat may play some part in the predisposition to thrombosis as well as to atherosclerosis formation, although the extent of this is not yet defined.

Other considerations in relation to thrombosis should be mentioned for the sake of completeness, although it would be out of place to consider them in detail in this survey devoted primarily to laboratory studies. Thrombosis is associated with certain clinical states, e.g. diabetes, hypertension, xanthomatosis and malignancy. It is also associated with a familial or racial tendency. From surveys it appears that cigarette smoking may predispose to thrombus formation. ${ }^{7,12}$ Insufficient physical exercise may also play a part as suggested by the occupational survey in London Transport workers by Morris. ${ }^{18}$

Thus a multiplicity of factors and influences are involved in the pathogenesis of thrombosis. Coagulability studies appear to be of importance, as do changes in the circulatory blood flow from the scanty evidence available. The extent of the role played by fats is not yet finally decided. Further research may result in the discovery of a 'trigger mechanism'. It is much more likely, however, that it will confirm the need to consider many different causes and influences in the problem of intravascular clotting.

\section{REFERENCES}

I. ALEXANDER, B. (1959), New Engl. F. Med., 260, 1288.

2. ALLEN, G. W., and ATTYAH, A. M. (1953), f. Lab. clin. Med., 41, 767 .

3. ASCHOFF, L. (1924), 'Lectures in Pathology', Paul B. Hoeber Inc., New York.

4. BIGGS, R., and DOUGLAS, A. S. (1953), F. clin. Path., 6, 23.

5. CREVELD, VAN S., and PAULSSEN, M. P. (1951), Lancet, ii, 242.

6. DODDS, C., and MILLS, G. L. (1959), Ibid., i, 1160.

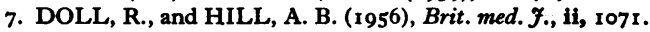

8. DUGUID, J. B. (1946), f. Path. Bact., 58, 207.

9. GARDIKAS, C., TSAKAYANNIS, F., and THOMPOULOS, D. (1959), Acta haemat. (Basel), 21, 129.

10. GOFMAN, J. W. (1959), 'Coronary Heart Disease', Blackwell Scientific Publications Ltd., Oxford.

11. HARRISON, C. V. (1948), f. Path. Bact., 60, 289.

12. HAMMOND, E. C., and HORN (1954), f. Amer. med. Ass., 155, 1316.

13. HEARD, B. E. (1952), F. Path. Bact., 64, 13.

14. INGRAM, G. I., BIGGS, R., and ARMITAGE (1953), 7. clin. Path., 6, 246.

15. LEMPERT, H., and POLLER, L., to be published.

16. MCDONALD, L. (1959), European Congress of Haematology, London, abstract.

17. MCDONALD, L., and EDGILL, M. (1957), Lancet, ii, 457. 18. MORRIS, J. N. (1958), Circulation, 17, 321.

19. OGURA, J. (1946), F. clin. Invest., 25, 486.

20. OWREN, P. (1959), Lancet, ii, 754.

21. PAYLING WRIGHT, G. (1954), 'An Introduction to Pathology', and ed., Longmans, Green and Co. Ltd., London.

22, POLLER, L. (1954), Angiology, 5, 21.

23. POLLER, L. (1956), Clin. Sci., 15, 55.

24. POLLER, L. (1957), f. clin. Path., 10, 348.

25. POLLER, L. (1960), Ibid., 13, 226.

26. POLLER, L. (1959), Ibid., 12, 331.

27. QUICK, A. J. (1935), f. biol. Chem., 109, 83.

28. SPOONER, M., and MEYER, O. O. (1945), F. Lab. clin. Med. 30, 390 .

29. WAUGH, T. R., and RUDDICK, D. W. (1944), Canad. med. Ass. F., 50, 547 .

30. WESSLER, S., BALLER, J. D., and GOLBERT, M. (1956), Э. clin. Invest., 35, 743 .

References continued from page $562-\mathcal{F} . R$. O'Brien, M.A., D.M., M.R.C.S., M.R.C.P.

7. BORN, G. V. R. (1958), Biochem. F., 68, 695.

8. BOUNAMEAUX, Y. (1957), Thromb. Diath. Haem., I, 209.

9. CHANDLER, A. B. (1958), Lab. Invest., 7, 1 ro.

ro. DAWSON, R. M. C., and BANGHAM, A. D. (1959), Biochem. $\boldsymbol{\mathcal { F }}$., 72, 493 .

I I. GORMSEN, J. (1959), Brit. F. Haemat., 5, 257.

12. HUGHES, J. (1953), Arch. int. Physiol., 6r, 565.

13. HUGHES, J. (1959), Thromb. Diath. Haem., 3, 34.

14. LUSCHER, E. F. (1959), Schweiz. med. Wschr., 89, 1021.

15. McDONALD, L., and EDGILL, M. (1959), Lancet, i, 1115.

16. MERSKY, C., GORDON, H., and LACKNER, H. (1960), Brit. med. Э., i, 219.

17. MASTER, A. M., DACK, S., and JAFFE, H. (1939), Amer. Heart $\mathcal{F}, \mathbf{1 8}, 434$.

18. MOOLTEN, S. E. L., VROMAN, L., VROMAN, S., and GOODMÁN, B. (I949), Arch. intern. Med., 84, 667.

19. MUSTARD, J. F. (1958), Canad. med. Ass. F., 79, 554.

20. NILSSON, I. M., BLOMBACK, M., and BLOMBACK, B. (1959), Acta med. scand., 164, 263.
21. NITZBERG, S. I., PEYMAN, A., GOLDSTEIN, R., and PROGER, S. (1959), Circulation (N.Y.), 19, 676.

22. O'BRIEN, J. R. (1958), Lancet, i, 410.

23. O'BRIEN, J. R. (1959), Nature (Lond.), 184, 1580.

24. O'BRIEN, J. R. (1960), unpublished work.

25. POOLE, J. C. F. (1959), Quart. F. exp. Physiol., 44, 377.

26. SAWYER, P. N., PATE, J. W., and WELDON, C. S. (1953), Amer. F. Physiol., 175, 108.

27. SCHWARTZ, S. I. (1959), Surg. Gynec. Obstet., 108, 533.

28. SHARP, A. A. (1958), Brit. F. Haemat., 4, 28.

29. WALDON, A., CHAPMAN, J. E., and EVANS, J. M. (1954), Amer. Heart $\mathcal{F}$, , 47, 563.

30. WRIGHT, H. P. (1942), F. Path. Bact., 54, 461.

31. ZUCKER, M. B., and BORRELLI, J. (1959), F. appl. Physiol., I4, 575 .

32. ZUCKER, M. B., and BORELLI, J. (1960), Thromb. Diath, Haem., 4, 424. 